\title{
Analysis on Influencing Factors of Dance Teaching Effect in Colleges Based on Data Analysis and Decision Tree Model
}

\author{
https://doi.org/10.3991/ijet.v15i09.14033
}

Beibei Guo

Central South University, Changsha, China

Management Shinawatra University, Bangkok, Thailand

gbbcsua163. com

\begin{abstract}
In colleges, dance teaching is influenced by a variety of factors. It is very difficult to clarify how much each factor impacts the teaching effect. To overcome the difficulty, this paper explores the factors affecting the dance teaching effect in colleges based on data analysis and decision tree model. Firstly, the authors enumerated the goals of dance teaching for college students in the new era, and then summed up the constraints on the influencing factors of dance teaching effect in colleges. On this basis, an analysis model was established for the influencing factors, while the corresponding extensible decision tree was set up and verified through example analysis. The research findings shed new light on the theories of dance teaching in colleges, and provide an analysis model with great application potential.
\end{abstract}

Keywords - Colleges, dance teaching, data analysis, decision tree, influencing factors

\section{Introduction}

Quality education is the mainstream of modern institutes of higher learning, opening up a way to cultivate all-round talents. This education mode has become a hotspot in the research of higher education [1-3]. Dance education is an important aspect of quality education in colleges. Besides the training of professional dancers, dance education helps to promote various abilities of college students, ranging from aesthetics to physique [4-5]. It is critical for colleges to implement dance education, and improve the quality and effect of dance teaching.

Dance education has attracted much attention from researchers. For example, Ana Dantas et al. [6] designed an exploratory hybrid method to test the factors that dancers think are related to physical dissatisfaction, and provided reference for dance teaching. Dania et al. [7] discussed the role of sports technology in dance education, examined the relevant practices, and predicted the future trends. Ganciu et al. [8] discussed the promoting effect of aerobic dance on the innovative ability of college students. Cahala et al. [9] investigated the dance exposure, health and injuries of today's col- 
lege students. Tian [10] explored how to train the sense of rhythm in college dance teaching.

The above studies mainly concentrate on the local links or skills of dance teaching. Nonetheless, the influencing factors of dance teaching effect have not been identified systematically, not to mention providing targeted improvement measures. In fact, the effect of dance teaching in colleges is affected by multiple factors. It is impossible to find and evaluate these factors, without a complex process of knowledge mining. However, the popular engineering mining strategies, namely, knowledge mining [11, $12]$, data mining [13, 14], association rule mining [15, 16], and decision trees [17, 18], face severe limitations in identifying the factors affecting dance teaching effect in colleges, owing to the various uncertainties in the analysis process and the fuzzy relationship between these factors.

Drawing on the relevant studies, this paper introduces the extension theory [19-22] and data analysis techniques [23-25] to examine the influencing factors of the dance teaching effect in colleges, and creates an extensible decision tree for such factors.

The remainder of this paper is organized as follows: Section 2 enumerates the goals of dance teaching in colleges in the new era; Section 3 sums up the constraints on the influencing factors of dance teaching effect in colleges; Section 4 establishes an analysis model for the influencing factors, and generates the extensible decision tree; Section 5 puts forward the conclusions.

\section{Analysis for Training goals of Dance Teaching for College Students in the New Era}

Combining with the development needs of the times, the dance teaching of college students in the new era should aim to train their dance quality from the following aspects.

\subsection{Training of dance expertise}

The first step in the training of senior talents is the cultivation of professional knowledge. The degree of professional knowledge directly determines the professional development potential and innovative ability of senior talents. Dance teaching is an important part of higher education. Dance knowledge is characterized by strong professionalism, systematicness, logicality, technique, and technicality. This requires the colleges to perform the related work as follows: First, carry out reasonable setting of the dance professional curriculum, that is, in the process of dance teaching for college students, it is necessary to classify dance professional knowledge, plan the content of dance teaching according to different dance learning stages, formulate a syllabus for college dance majors, and compile textbooks or books with strong professional knowledge of dance; secondly, improve the faculty of college dance teaching, i.e., introduce high-level dance teachers, increase the funding for college dance teaching, and build a dance teaching platform and infrastructure for college students, thus forming a modern dance teaching team with sustainable development capabilities. 


\subsection{Training of dance performance consciousness}

Dance is a professional discipline in higher education that requires very high standards of movement and skills. It has high artistic requirements. This requires exhibiting the importance of performance consciousness in the dance teaching process of college students, and highlighting its appeals in dance display. For this reason, in the dance teaching process of college students, different forms based on characters, scenes, or plots, etc. should be used to reflect the emotions and inner thoughts of various characters, shape the character's true performance under special circumstances, demonstrate the dance penetration that matches the personality or specialty of the character, and then renders the life reality that the dance wants to express, thereby resonating with the audience from the soul of the performer. Obviously, the college students' consciousness of dance performance cannot be achieved overnight. Attention should be paid to the unity and integration of dance content and form in the dance teaching process, and the coordination between the beauty of dance image and the setting of dance movement. Also, the artistic conception or spirituality of the dance performance need to planned and fully displayed in the dance teaching, so that college students can always experience this appeal in the dance learning process, and then achieve a subtle dance learning effect.

\subsection{Training of dance expressiveness}

Dance expressiveness is the ability of college student to perform dance works. Compared with dance performance consciousness, both need to emphasize the understanding and absorption of dance works by college student performers, and then display the penetration and infection of dance works. But the difference is that dance performance consciousness is the fusion and display of the inherent thoughts or implicit cultural characteristics of dance works, focusing on the underlying characteristics of a dance culture or dance temperament, while dance expressiveness is the fusion and display of external forms of dance works, emphasizing on the image characteristics of a dance performance. Thus, during the dance teaching of college students, it is often necessary to design the artistic image of the dance performer based on different cultural backgrounds, different regional environments, different scene settings, and different performance forms, etc. from the aspects of the performer's image selection, dance technical action planning, dance language expression form setting and others. These can form an organic performance as a whole, so as to reflect the spiritual content and artistic expression of dance works. For this reason, the dance teaching process of college students should not only pay attention to the cultivation of college students' personal artistic images, and improve their dance aesthetics, but also strengthen the performers' cultural understanding and control of dance rhythm.

\subsection{Training of dance innovation ability}

The dance works that are separated from real life have no soul; such works have no artistic appreciation value and cannot be passed on to the world. Dance works that are 
detached from the society have no appeal; such dance works are not competitive in the times and cannot be accepted by the general public. As the era is constantly developing, and the society is also constantly progressing, the social connotations that dance works in each era can often show will be weakened or forgotten with the changes of the society. The creation of the dance works conforming to the times and social life requires innovation in them. Therefore, in the dance teaching process, it is necessary to concentrate on cultivating the innovative ability of college student performers, so that they can have the ability to independently undertake the creation of dance works, innovate or re-create dance works in the contexts of different cultural backgrounds, different regional environments, different scene settings, and different performance forms. For improving the dance innovation ability of college students, it is necessary to enhance their learning ability, understanding ability and practical ability in the dance teaching process, encourage them to participate in the creative process of dance works, and combine their life with the creative process of dance works, thereby integrating the dance professional knowledge of college students with the creation and performance of dance works together.

\section{Analysis for Constraints on the Influential Factors of Dance Teaching Effect for College Students}

There are many factors influencing the effect of dance teaching in colleges. By reviewing relevant literature and consulting experts and scholars in the field, the authors summed up the constraints on the influencing factors of dance teaching effect in colleges.

1. Software and hardware strength of dance teaching. In this respect, it need to consider the faculty of the dance teaching in colleges, the construction of dance teaching talents, the professional ability of dance teachers, the hardware support for dance teaching, and the investment in dance teaching reforms and so on.

2. Dance teaching mode. The influencing factors in this regard need to consider whether dance teaching in colleges has advanced ideas of dance education; whether the theory of dance teaching is scientific; whether the process of dance teaching activities has a stable structural form; whether the dance teaching is guided by corresponding learning theories, etc.

3. Dance teaching contents. It needs to consider whether the content of dance teaching in colleges is conducive to the cultivation of psychological state and psychological function for college students; whether the content of dance teaching is backward, detaches from social development needs, and meets the training needs of dance talents in modern higher education; whether the teaching materials meet the requirements of quality education and the teaching goals; whether the dance teaching curriculum outline is in line with the discipline construction plan; whether the dance curriculum task schedule is reasonable; whether the fine course construction of dance teaching satisfies the requirements of professional settings; whether dance teaching resources are abundant, etc. . 
4. Dance teaching means. The influencing factors in this regard need to consider whether the dance teaching means for college students meet the requirements of modern multifunctional teaching; whether the dance teaching means are diversified (using artificial intelligence, virtual reality, computers, multimedia, cameras and other technologies or equipment); whether the dance teaching has applicability, not just for show; the application rate of intelligent teaching methods for dance teaching and the application of students and so on.

5. Dance teaching methods. For the dance teaching methods, the constraints mainly include: whether there are diversified dance teaching methods for college students; the application of Internet+-based network technology, the level and ability of information construction, and the construction level of courseware such as flipped classrooms and MOOC-based classes, and the openness of dance teaching platform in dance teaching; whether the dance teaching method is conducive to the integration of the sense of music, form, and dance quality of college students; whether the dance teaching method is conducive to the college students' awareness of dance culture, etc.

6. Dance teaching management system. In this regard, it needs to consider the rationality of the establishment of dance teaching administrative functions and management institutions in colleges, the allocation of full-time dance teachers and the construction of management platforms, and the setting of the student management organization in dance teaching.

7. Dance teaching quality. The constraints in this respect are: whether the teacher's teaching attitude is correct, the teaching manner is appropriate and civilized in the dance teaching process for college students; whether the classroom atmosphere of dance teaching can mobilize the enthusiasm of the students, and stimulate their interest in learning; whether the dance is taught effectively in the aspects of dance knowledge, dance movements, dance skills, emotion and rhythm control, and dance expressiveness, etc.; whether the teaching content is specifically taught in accordance with the individual conditions of the students, e.g., some students have a weak sense of rhythm, a weak sense of music, or a low ability to accept new knowledge and so on.

8. Dance teaching reform. In this respect, it needs to consider the continuity and integration between the traditional and modern course of dance teaching in colleges; the impact of the dance teaching reforms they have undertaken and the results of dance teaching reforms; the combination between the dance teaching reforms and scientific research; whether the transformation effect of dance teaching reform and research results can effectively promote the creation of new dance works; whether the theory and practice of dance teaching are disjointed; whether the dance teaching reform effectively promotes the employment or further education of dance majors.

9. Scientific research on dance teaching. The influencing factors in this regard need to consider the epochal character of the scientific research on dance teaching for college students, the influence of the scientific research topics for dance teaching undertaken, the scientific research results of dance teaching, the construction of the 
scientific research platform, dance majors' participation in dance science research topics, and the cultivation of innovative abilities etc.

10. Student factors in dance teaching. In terms of the student factors in dance teaching, it needs to consider the dance foundation of college dance majors, the music foundation of dance majors, their physical foundation, the learning interest, the learning attitude, and the ability to absorb professional knowledge and so on.

11. Evaluation of dance teaching effect. The constraints on influencing factors in this regard include: whether the evaluation system of dance teaching effect for college students is scientific; whether the evaluation model of dance teaching effect is effective; the accuracy and reliability of the evaluation results of dance teaching effect; whether the evaluation process of the dance teaching effect is fair and transparent; whether the effect evaluation results can effectively promote the teaching quality etc.

\section{Establishment and Application of an Analysis Model for Influencing Factors of Dance Teaching Effects in Colleges}

\subsection{Research methods and data acquisition}

The accurate and reliable data are required for effectively analyzing the influencing factors of dance teaching effects for college students. The acquisition of these data needs to be considered in two aspects: the type and style of data; the methods used to obtain the data for this analysis. In terms of the data types, generally there are two types of data for analysis, namely precise data and fuzzy data: precision data refers to the values that can accurately describe the dance teaching effects for college students, while fuzzy data refers to the parameter values which is difficult to determine the dance teaching effect, which generally need to be described by fuzzy values; in terms of style, it generally includes points, intervals, charts, models, texts, and other forms, but the data in the forms of charts, models, and texts etc. can generally extract the values of point or interval.

In terms of research methods, a questionnaire survey was conducted to acquire the data about the influencing factors of college students' dance teaching effect, and a combination of literature data, expert interview, and mathematical statistical analysis methods were used to analyze these data. By selecting certain college students as respondents, the questionnaire survey method was conducted mainly to obtain the results of the respondents, and then achieve the influence degree of factors on dance teaching effects in colleges. Literature data methods, expert interview methods, and mathematical statistical analysis methods were used as auxiliary data acquisition methods for influencing factors to resolve some of the analytical data that is difficult to obtain through normal methods or methods, and translate them into a form that can be integrated with data obtained from the questionnaire survey. 


\subsection{Option settings for data analysis}

As above, this paper designs a table for the data analysis of influencing factors on the effect of dance teaching for college students. The specific content and form are shown in Table 1.

In Table 1, those factors were rated by many assessors. It mainly included experts and scholars in the social field, college leaders and teachers, and employment units or institutes for further study of the dance majors. During the survey process, different assessors may give different scoring weights. For this, analysis can be performed by giving a correlation degree in the questionnaire items, that is, mainly the correlation between the assessors and the influencing factors. The degree of correlation can determine its weight. If the assessor has a strong correlation with the influencing factor, the weight of this factor shall be higher; otherwise, the weight shall be lower. If the assessors' importance varies insignificantly in the scoring process, the equal weight method is often used. The authors also adopt this method. In addition, the influencing degree of dance teaching effects for college students needs to be rated. This mainly refers to the influence degree of factors on teaching effects, whether it is indispensable and optional. Then, it's further divided into three levels: perfect influencing factors, ordinary influencing factors and weak influencing factors, ranging from $0-100$; the value is positively correlated with the degree of importance.

Table 1. Data analysis

\begin{tabular}{|l|c|c|c|l|}
\hline \multirow{2}{*}{ Factors } & \multicolumn{3}{|c|}{ Assessors } & Comprehensive \\
\cline { 2 - 4 } & $\begin{array}{c}\text { Experts and } \\
\text { scholars }\end{array}$ & $\begin{array}{c}\text { College } \\
\text { leaders and } \\
\text { teachers }\end{array}$ & $\begin{array}{c}\text { Employment } \\
\text { units or institu- } \\
\text { tions }\end{array}$ & $\begin{array}{l}\text { Cores } \\
\text { Software and hardware strength of } \\
\text { dance teaching } C_{1}\end{array}$ \\
\hline Dance teaching mode $C_{2}$ & 60 & 80 & 80 & 73.333 \\
\hline Dance teaching content $C_{3}$ & 85 & 90 & 100 & 91.667 \\
\hline Dance teaching means $C_{4}$ & 90 & 90 & 100 & 93.333 \\
\hline Dance teaching methods $C_{5}$ & 90 & 95 & 85 & 90 \\
\hline Dance teaching management system $C_{6}$ & $40-60$ & 80 & 85 & 90 \\
\hline Dance teaching quality $C_{7}$ & $90-100$ & 100 & $40-60$ & $53.333-66.667$ \\
\hline Dance teaching reform $C_{8}$ & 80 & 80 & 100 & $96.667-100$ \\
\hline Scientific research on dance teaching $C_{9}$ & $60-80$ & 70 & 60 & 73.333 \\
\hline Student factors in dance teaching $C_{10}$ & 50 & 60 & 60 & $63.333-70$ \\
\hline Evaluation of dance teaching effect $C_{11}$ & 50 & 70 & $40-60$ & $50-56.667$ \\
\hline
\end{tabular}

\subsection{Generation and application of extensible decision tree}

After obtaining the comprehensive scores, this paper performs a decision analysis on the influencing factors of the dance teaching effect for college students based on the extension theory. Extension theory is an intelligent subject that studies the possibility of expanding things and developing innovative laws. It uses extension mathematics as its mathematical logic foundation and provides quantitative analysis tools 
for decision analysis of complex problems; especially, the extension distance and extension correlation function in extension theory can well handle the positional relationship between the interval numbers of fuzzy information in fuzzy decision analysis. Therefore, it has a good adaptability for resolving the decision analysis for influencing factors of dance teaching effects in colleges.

Let the value of the influential factors $i$ be vi, the classical domain $j$ of extensible decision analysis for influencing factors of dance teaching effects is $V_{\Omega(j)}=\left[v_{\Omega(j)}^{l e f}, v_{\Omega(j)}^{r i g}\right]$, and then the extension distance between the influencing factors $i$ and the classical domain $\mathrm{j}$ is given as:

$$
\rho\left(v_{i}, V_{\Omega(j)}\right)=\left|v_{i}-\frac{v_{\Omega(j)}^{\text {lef }}+v_{\Omega(j)}^{\text {rig }}}{2}\right|-\frac{1}{2}\left(v_{\Omega(j)}^{\text {rig }}-v_{\Omega(j)}^{\text {lef }}\right)
$$

If the joint domain of extensible decision analysis is $V_{\Omega(o)}=\left[v_{\Omega(o)}^{\text {lef }}, v_{\Omega(o)}^{\text {rig }}\right]$, and $v_{\Omega(o)}^{l e f} \leq v_{\Omega(o)}^{r i g}$, then the extension distance between the influential factors i and joint domain is given as:

$$
\rho\left(v_{i}, V_{\Omega(o)}\right)=\left|v_{i}-\frac{v_{\Omega(o)}^{l e f}+v_{\Omega(o)}^{r i g}}{2}\right|-\frac{1}{2}\left(v_{\Omega(o)}^{r i g}-v_{\Omega(o)}^{l e f}\right)
$$

If the value of the influential factors $i$ is $v_{i}=\left[v_{i}^{\text {lef }}, v_{i}^{\text {rig }}\right], v_{i}^{\text {lef }} \leq v_{i}^{\text {rig }}$, and the classical domain $\mathrm{j}$ of extension decision analysis for influential factors is $V_{\Omega(j)}=\left[v_{\Omega(j)}^{l e f}, v_{\Omega(j)}^{\text {rig }}\right], v_{\Omega(j)}^{\text {lef }} \leq v_{\Omega(j)}^{\text {rig }}$, then the extension distance between the influencing factors $i$ and the classical domain $\mathrm{j}$ is shown as:

$$
\begin{aligned}
& \rho\left(v_{i}, V_{\Omega(j)}\right)=\frac{\rho\left(v_{\left.v_{2(j)}^{\prime \prime j}\right)}, V_{\Omega(j)}\right)+\rho\left(v_{\Omega(j)}^{r i g}, V_{\Omega(j)}\right)}{2}
\end{aligned}
$$

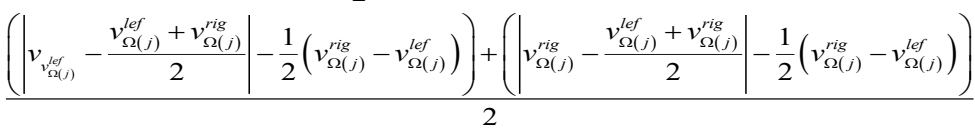

If the joint domain of extension decision analysis for influential factors $\mathrm{i}$ is $V_{\Omega(o)}=\left[v_{\Omega(o)}^{l e f}, v_{\Omega(o)}^{r i g}\right], v_{\Omega(o)}^{l e f} \leq v_{\Omega(o)}^{r i g}$, then the extension distance between the influencing factors $i$ and the joint domain is shown as: 


$$
\begin{aligned}
& \rho\left(v_{i}, V_{\Omega(o)}\right)=\frac{\rho\left(v_{v_{\Omega(j)}^{\text {lef }}}, V_{\Omega(o)}\right)+\rho\left(v_{\Omega(j)}^{r i g}, V_{\Omega(o)}\right)}{2} \\
& \frac{\left(\left|v_{v_{\Omega(j)}^{\text {lef }}}-\frac{v_{\Omega(o)}^{l e f}+v_{\Omega(o)}^{r i g}}{2}\right|-\frac{1}{2}\left(v_{\Omega(o)}^{r i g}-v_{\Omega(o)}^{l e f}\right)\right)+\left(\left|v_{v_{\Omega(j)}^{\text {lef }}}^{\text {ref }}-\frac{v_{\Omega(o)}^{l e f}+v_{\Omega(o)}^{r i g}}{2}\right|-\frac{1}{2}\left(v_{\Omega(o)}^{r i g}-v_{\Omega(o)}^{l e f}\right)\right)}{2}
\end{aligned}
$$

Also, the extension correlation coefficient between the influencing factors $i$ and the classical domain $\mathrm{j}$ is given as:

$$
K_{i}\left(V_{\Omega(j)}\right)= \begin{cases}\frac{-\rho\left(v_{i}, V_{\Omega(j)}\right)}{\left|V_{\Omega(j)}\right|} & v_{i} \in V_{\Omega(j)} \\ \frac{\rho\left(v_{i}, V_{\Omega(j)}\right)}{\rho\left(v_{i}, V_{\Omega(o)}\right)-\rho\left(v_{i}, V_{\Omega(j)}\right)} & v_{i} \notin V_{\Omega(j)}\end{cases}
$$

If the influencing factors of dance teaching effects for college students have multilevel structural characteristics, then there are multiple sub-level influencing factors in the same level, and the comprehensive correlation coefficient is:

$$
K\left(V_{\Omega(j)}\right)=\sum_{i=1}^{n}\left(w_{i} * K_{i}\left(V_{\Omega(j)}\right)\right)
$$

From this, the authors obtained the comprehensive sequence of the extension correlation coefficients between the influential factors and each classical domain. According to this sequence, the corresponding influencing factors were retained for those meeting the threshold requirements of the classical domain, otherwise they were classified into the next level, that is, the first-level factors are selected according to the threshold of the perfect influencing factor; second-level factors are selected according to the threshold of ordinary influencing factors; the third-level factors are selected according to the threshold of the weak influencing factor; the same processing method for each level of factors was used to obtain a multi-level extension decision tree. For the higher-level influencing factor, it has a great impact on the teaching effect, so the existing problems therein should be solved first; for the influential factors within a certain level, the higher the level, the greater the impact on the upper level; to solve the existing problems in the upper level of influencing factor, priority should be given to this factor.

As above, there are perfect influencing factors, ordinary influencing factors, and weak influencing factors. Accordingly, the extensible decision analysis of influencing factors of dance teaching effects for college students defines their classical domains as $\Omega_{\text {perf }}, \Omega_{\text {ordi } i \text { and }} \Omega_{\text {weak }}$, and the relevant joint domain as $\Omega_{\text {enti }}$, which are shown as: 


$$
\left\{\begin{array}{l}
\Omega_{\text {perf }}=[80-100] \\
\Omega_{\text {ordi }}=[60-80] \\
\Omega_{\text {weak }}=[0-60] \\
\Omega_{\text {enti }}=[0-100]
\end{array}\right.
$$

Since the calculation process of influencing factors at each level is exactly the same, the author only performed the analysis for the level-1 influencing factors. Based on the above model, the calculation results of the extension correlation coefficient were obtained, as shown in Table 2.

Table 2. Extension correlation coefficients

\begin{tabular}{|l|c|c|c|}
\hline \multirow{2}{*}{ Factors } & \multicolumn{2}{c|}{ Classical domain } \\
\cline { 2 - 4 } & $\boldsymbol{\Omega}_{\text {perf }}$ & $\boldsymbol{\Omega}_{\text {ordi }}$ & $\boldsymbol{\Omega}_{\text {weak }}$ \\
\hline Software and hardware strength of dance teaching $C_{1}$ & -0.200 & 0.334 & -0.333 \\
\hline Dance teaching mode $C_{2}$ & 0.417 & -0.583 & -0.792 \\
\hline Dance teaching content $C_{3}$ & 0.334 & -0.667 & -0.833 \\
\hline Dance teaching means $C_{4}$ & 0.500 & -0.500 & -0.750 \\
\hline Dance teaching methods $C_{5}$ & 0.500 & -0.500 & -0.750 \\
\hline Dance teaching management system $C_{6}$ & -0.333 & 0 & 0 \\
\hline Dance teaching quality $C_{7}$ & 0.083 & -0.917 & -0.958 \\
\hline Dance teaching reform $C_{8}$ & -0.200 & 0.334 & -0.333 \\
\hline Scientific research on dance teaching $C_{9}$ & -0.286 & 0.334 & -0.167 \\
\hline Student factors in dance teaching $C_{10}$ & -0.364 & -0.125 & 0.111 \\
\hline Evaluation of dance teaching effect $C_{11}$ & -0.350 & -0.071 & 0.056 \\
\hline
\end{tabular}

Based on the physical meaning of the extension correlation function, it can be seen that if the decision object falls within the classical domain, its extensive correlation coefficient with the classical domain is positive; otherwise it is negative, so the influencing factors in each classical domain can be determined. Thus, the first-level extensible decision tree of influencing factors was formed, as shown in Fig. 1. 


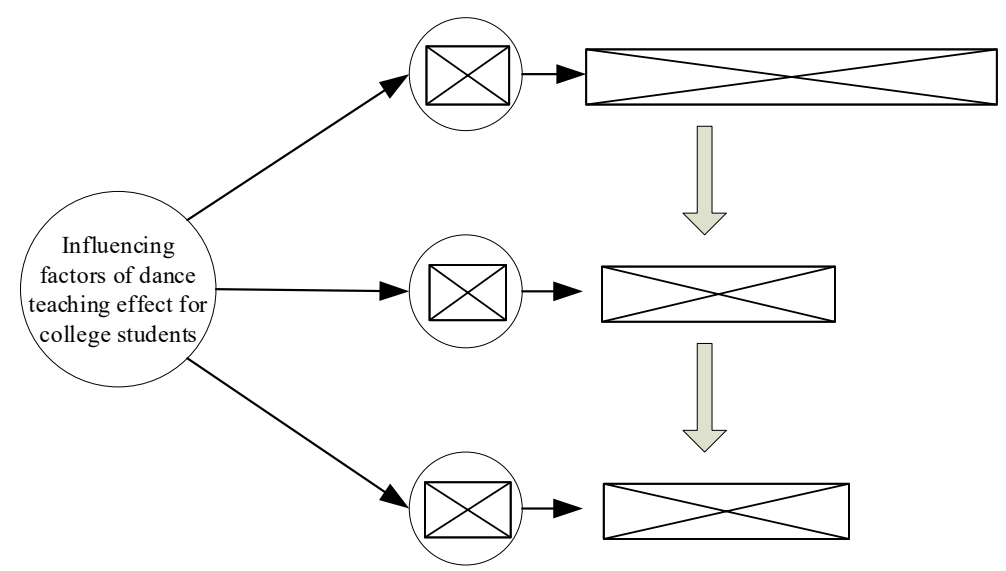

Fig. 1. The extensible decision tree of influencing factors of dance teaching effect for college students

\section{Conclusion}

Combining the extension theory with data analysis and decision tree methods, the authors enumerated the goals of dance teaching for college students in the new era, and then summed up the constraints on the influencing factors of dance teaching effect in colleges. On this basis, an analysis model was established for the influencing factors, and then the corresponding extensible decision tree was set up and verified through example analysis. The analysis method and model of influencing factors given in this paper are well targeted, which can effectively find out the relatively weak links of dance teaching for college students and form corresponding improvement strategies. Therefore, their good adaptability is verified.

\section{References}

[1] Rubio-Alcalá, F. D., Arco-Tirado, J. L., Fernández-Martín, F. D., López-Lechuga, R., Barrios, E., \& Pavón-Vázquez, V. (2019). A systematic review on evidences supporting quality indicators of bilingual, plurilingual and multilingual programs in higher education. Educational Research Review, 27, 191-204. https://doi.org/10.1016/j.edurev.2019.03.003

[2] Kurilovas, E. (2018). On data-driven decision-making for quality education. Computers in Human Behavior, 1-9. https://doi.org/10.1016/j.chb.2018.11.003

[3] Sari, A., Firat, A., \& Karaduman, A. (2016). Quality assurance issues in higher education sectors of developing countries; Case of Northern Cyprus. Procedia-Social and Behavioral Sciences, 229, 326-334. https://doi.org/10.1016/j.sbspro.2016.07.143

[4] Karageorghis, C. I., Lyne, L. P., Bigliassi, M., \& Vuust, P. (2019). Effects of auditory rhythm on movement accuracy in dance performance. Human movement science, 67, 1-11. https://doi.org/10.1016/j.humov.2019.102511 
[5] Pastore, S., \& Pentassuglia, M. (2015). Teaching as dance: A case-study for teacher practice analysis. International Journal of Educational Research, 70, 16-30. http://doi.org/ 10.1016/j.ijer.2014.12.001

[6] Dantas, A. G., Alonso, D. A., Sánchez-Miguel, P. A., \& del Río Sánchez, C. (2018). Factors dancers associate with their body dissatisfaction. Body image, 25, 40-47. https:// doi.org/10.1016/j.bodyim.2018.02.003

[7] Dania, A., Hatziharistos, D., Koutsouba, M., \& Tyrovola, V. (2011). The use of technology in movement and dance education: Recent practices and future perspectives. Procedia-Social and Behavioral Sciences, 15, 3355-3361. http://doi.org/ 10.1016/j.sbspro. 2011.04.295

[8] Ganciu, M., \& Ganciu, O. M. (2014). Development of the creative capacity by means of aerobic dance in higher deadlock education. Procedia-Social and Behavioral Sciences, 163, 110-114. https://doi.org/ 10.1016/j.sbspro.2014.12.294

[9] Cahalan, R., Kearney, P., Bhriain, O. N., Redding, E., Quin, E., McLaughlin, L. C., \& O'Sullivan, K. (2018). Dance exposure, wellbeing and injury in collegiate Irish and contemporary dancers: A prospective study. Physical Therapy in Sport, 34, 77-83. https:// doi.org/10.1016/j.ptsp.2018.09.006

[10] Tian, H. (2019). How to cultivate students' rhythm consciousness in college dance teaching. Journal of Yanbian Institute of Education, 33(5), 41-42.

[11] Boje, C., \& Li, H. (2018). Crowd simulation-based knowledge mining supporting building evacuation design. Advanced Engineering Informatics, 37, 103-118. https://doi.org/10.10 16/j.aei.2018.05.002

[12] Idoudi, R., Ettabaa, K. S., Solaiman, B., \& Hamrouni, K. (2016). Ontology knowledge mining based association rules ranking. Procedia Computer Science, 96, 345-354. https:// doi.org/10.1016/j.procs.2016.08.147

[13] Pan, L. (2019). A big data-based data mining tool for physical education and technical and tactical analysis, International Journal of Emerging Technologies in Learning, 14(22): 220231. https://doi.org/10.3991/ijet.v14i22.11345

[14] Gholami, H., Mohamadifar, A., \& Collins, A. L. (2020). Spatial mapping of the provenance of storm dust: Application of data mining and ensemble modelling. Atmospheric Research, 233, 1-17. https://doi.org/10.1016/j.atmosres.2019.104716

[15] Altay, E. V., \& Alatas, B. (2020). Intelligent optimization algorithms for the problem of mining numerical association rules. Physica A: Statistical Mechanics and its Applications, 540, 1-11. https://doi.org/10.1016/j.physa.2019.123142

[16] Vougas, K., Sakelaropoulos, T., Kotsinas, A., Foukas, G. R. P., Ntargaras, A., Koinis, F., \& Georgoulias, V. (2019). Machine learning and data mining frameworks for predicting drug response in cancer: An overview and a novel in silico screening process based on association rule mining. Pharmacology \& therapeutics, 203, 1-28. https://doi.org/10.1016/j. pharmthera.2019.107395

[17] De Mello, R. F., Manapragada, C., \& Bifet, A. (2019). Measuring the Shattering coefficient of Decision Tree models. Expert Systems with Applications, 137, 443-452. https://doi.org/10.1016/j.eswa.2019.07.012

[18] Sikder, S., Metya, S.K., Goswami, R.S. (2019). Exception-tolerant decision tree / rule based classifiers. Ingénierie des Systèmes d'Information, 24(5): 553-558. https://doi.org/ 10.18280/isi.240514.

[19] Seyedmohammadi, J., Sarmadian, F., Jafarzadeh, A. A., \& McDowell, R. W. (2019). Development of a model using matter element, AHP and GIS techniques to assess the suitability of land for agriculture. Geoderma, 352, 80-95. https://doi.org/10.1016/j.geoder $\underline{\text { ma.2019.05.046 }}$ 
[20] Chao, K. H. (2014). An extension theory-based maximum power tracker using a particle swarm optimization algorithm. Energy conversion and management, 86, 435-442. http:// doi.org/10.1016/j.enconman.2014.05.018

[21] Wang, T., He, Q. Y., Wang, D. S., Adeyeye, K., Yu, P. (2019). Extension theory for the reconstruction of traditional villages: case example in Dawa village. Procedia Computer Science, 162, 191-198. https://doi.org/10.1016/j.procs.2019.11.275

[22] Du, Y. B., Zheng, Y. S., Wu, G. A., Tang, Y. (2020). Decision-making method of heavyduty machine tool remanufacturing based on AHP-entropy weight and extension theory. Journal of Cleaner Production, 252, 1-12. https://doi.org/10.1016/j.jclepro.2019.119607

[23] Wang, Z., Liu, J. (2019). A teaching quality evaluation system of massive open online courses based on big data analysis, International Journal of Emerging Technologies in Learning, 14(14): 81-91. https://doi.org/10.3991/ijet.v14i14.10818

[24] Rendall, R., Chiang, L. H., \& Reis, M. S. (2019). Data-driven methods for batch data analysis-A critical overview and mapping on the complexity scale. Computers \& Chemical Engineering, 124, 113. https://doi.org/10.1016/j.compchemeng.2019.01.014.

[25] Heidari, S., Naseri, M., Gheibi, R., Baghfalaki, M., Pourarian, M.R., Farouk, A. (2017). A new quantum watermarking based on quantum wavelet transforms. Communications in theoretical Physics, 67(6): 732. https://doi.org/10.1088/0253-6102/67/6/732

\section{$7 \quad$ Author}

Beibei Guo, PhD student of Management School of Management Shinawatra University, Bangkok, Thailand, now works at School of Architecture and Art, Central South University, Changsha 410083, China and mainly engages in choreographer, modern dance, dance therapy. gbbcsu@163.com

Article submitted 2020-02-17. Resubmitted 2020-03-05. Final acceptance 2020-03-05. Final version published as submitted by the authors. 